science and reason as a way of replacing religion and spirituality. These are challenging notions but powerfully argued.

Overall this is a broadly ranging book. At times it is academically dense and at times emotionally moving. I was left with a picture of a man who was curious, intellectually challenging of established theory and practice, and unafraid to question deeply held views. His arguments are intellectually rigorous, extensively researched and intellectually erudite. Although not a book for reading from cover to cover, it does offer ample opportunities for visiting a wide variety of areas concerning love and aggression. The book is not always an easy read, but it does repay the effort involved.

Siobhan Murphey Southern General Hospital, Department of Psychiatry,

1345 Govan Road, Glasgow G51 4TF, UK. Email: siobhan.murphy@ggc.scot.nhs.uk

doi: 10.1192/bjp.bp.112.110015

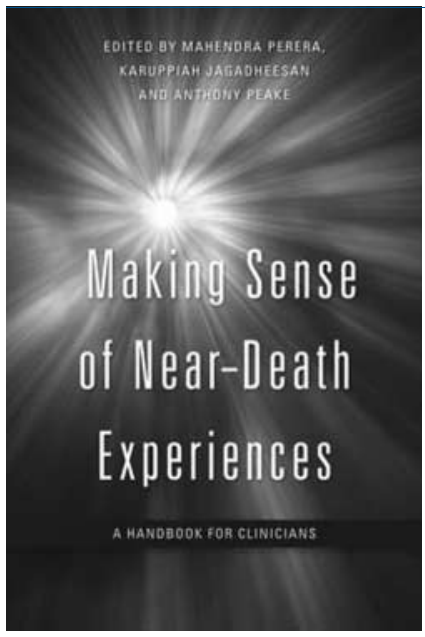

\section{Making Sense}

of Near-death

Experiences:

\section{A Handbook for Clinicians}

Edited by Mahendra Perera,

Karuppiah Jagadheesan

\& Anthony Peake.

Jessica Kingsley Publishers. 2011.

f18.99 (pb). $176 \mathrm{pp}$

ISBN: 9781849051491

Near-death experiences are a fascinating phenomenon, often shrouded in mystery and spirituality. The aims of this book are to give examples of this experience across different cultures and age ranges and to explore how this presents and can be managed in everyday clinical practice. Furthermore, and most interestingly, the book explores some of the possible scientific explanations behind this occurrence. The book as a whole was easy to read, and the structure made it very easy to dip in and out of. However, there was considerable repetition that was probably unavoidable given that this is a multi-author text.

A few chapters are dedicated to explaining the origins of near-death experiences. At times, these biological explanations are very basic for the medically trained professional. However, some explanations that attempt to enlighten how the mind may exist independently of the body derive from quantum physics. This possibility has profound implications for our concepts of consciousness and, potentially, even life and death themselves.

So how does this book help us as psychiatrists? The intense effect a near-death experience has on a person after such an event is often what we may have to deal with in what is a surprisingly common experience. Also, we need to understand such presentations to ensure we do not misdiagnose someone as having a mental illness on this basis. However, the true strength of the book does not lie with its application to clinical practice, but in the introduction to the biological and physical possible origins of such events. This turns this phenomenon from something you would only hear about in science fiction to scientific possibility. However, as the book acknowledges, there is still a lot of work to be done, but what fundamental repercussions this further work may have for us as psychiatrists and human beings cannot be underestimated - this book makes you believe that there just may be something more to this, and historic times may lie ahead. This is a truly thought-provoking read.

Rebecca Russell Birmingham and Solihull Mental Health NHS Foundation Trust, Birmingham, UK. Email: rebecca.russell@bsmhft.nhs.uk

doi: 10.1192/bjp.bp.112.110155

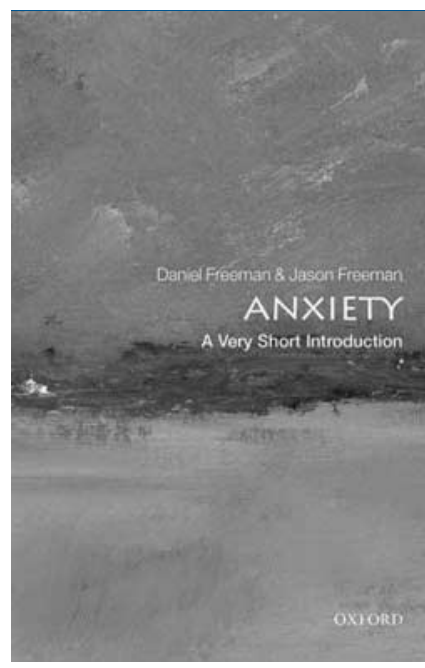

\section{Anxiety: \\ A Very Short Introduction}

By Daniel Freeman

\& Jason Freeman.

Oxford University Press. 2012

f7.99 (pb). $155 \mathrm{pp}$.

ISBN: 9780199567157

This book is the latest volume of the series 'Very Short Introductions', which covers a diverse range of topics from biblical archaeology to witchcraft. It is written by two brothers, Daniel and Jason Freeman, the former a consultant clinical psychologist and the latter an editor and author specialising in popular psychology and self-help.

Over the course of 11 chapters, the Freeman brothers cover the psychoanalytic, behavioural, cognitive and neurobiological theories of anxiety, before dedicating a further chapter to each of the major anxiety disorders, such as generalised anxiety disorder, panic disorder and obsessive-compulsive disorder. The final chapter describes the treatment options available, before presenting the reader with a number of self-assessment questionnaires, references and suggestions for further reading.

One of the appealing features of this book is the way in which it colours hard fact and theory with interesting historical asides, while peppering references to anxiety in literature, television and film alongside references to anxiety disorders in peer-reviewed journals.

The inclusion of case studies, as well as first-person narratives from household names such as Michael Palin, compliments some of the more heavy concepts and facts presented and helps put them into context. It also provides the reader with an identifiable figure with whom to relate and empathise with.

As a core trainee between part I and part II of the MRCPsych examinations, I found this book a refreshing read, putting into perspective information I had read from other sources with a more solid but dry academic grounding. My only criticism is that I am unsure of who the ideal reader for this book would be. In a sense the book suffers from a Goldilocks-type dilemma. It is not rigorous or comprehensive enough for medical students or trainees working towards their MRCPsych, yet I wonder whether it would be a little too academic for the average member of the public. 
However, it was an enjoyable read as an adjunct to core texts. I would also recommend this book to patients with a relatively high level of education and an interest in learning more about anxiety.

David McLaughlan Bloomsfield Centre, Guys Hospital, South London and Maudsley Trust, London SE1 9RT, UK. Email: david.mclaughlan@slam.nhs.uk

doi: 10.1192/bjp.bp.112.117127

\section{Years of the IPA}

The Centenary History of the Internationa Psychoanalytical Association 1910-2010

Evolution and Change

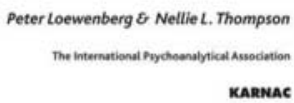

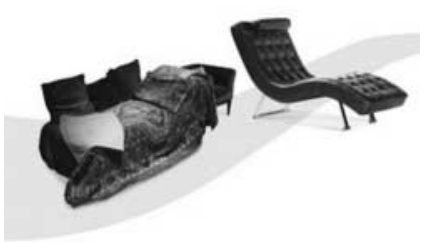

100 Years of the IPA. The Centenary History of the International Psychoanalytical Association, 1910-2010: Evolution and Change

Edited by Peter Loewenberg \& Nellie L. Thompson. £45.00 (pb). 570pp. ISBN: 9781905888160 Karnac Books. 2011.

The International Psychoanalytical Association (IPA) was founded in 1910. At that stage there were fewer than 100 members, most of whom were friends or colleagues. Despite its modest size there was no shortage of prestige - it was founded by Sigmund Freud, on an idea proposed by Sándor Ferenczi. The first president was Carl Jung and its first secretary was Otto Rank. Other founding members included Max Eitingon and Karl Abraham. Today, it is an association that counts 12000 psychoanalysts as members and works with 70 constituent organisations. It is recognised as the world's primary accrediting and regulatory body for psychoanalysis and takes an active role in the development of psychoanalytic thought and practice throughout the world.

2010 was the centenary year of the IPA and is marked by the publication of this book, a collection of essays from 41 of the member nations, each describing their own history and development within their particular geographical area. The psychoanalytic world is broadly split into four within the book: Europe, North America, Latin America and Asia and Oceania together.

The book begins with an essay from the Viennese branch of the IPA and the subsequent chapters trace the story of the growth and development of not just the IPA, but psychoanalytic thought and practice, outwards from Vienna and across the globe. It thus provides not just a history of the constituent member organisations, but an interesting account of the interplay between the social, cultural and political factors that both shaped, and were shaped by, the spread of an understanding of the unconscious.

For those with an interest in psychoanalysis or psychotherapy, the rich historical detail and the linking of advances to the context of the time provides both a fascinating read and much to consider in terms of how and why psychoanalysis in the reader's own patch may have reached where it has. For those working within the National Health Service (NHS) in the UK today, the book serves as a timely reminder of how the history of psychoanalysis is one of periods of enthusiasm and uptake followed by waning interest or attack, often to the point that it seems as though survival is threatened. Splits and divisions are commonplace. Throughout, however, is a clear message that in some form or another psychoanalytic thought and practice not only survives, but spreads and grows.

The collected histories of the member organisations provide many examples of how survival often requires history to be processed to allow the required change. Also highlighted is the need for innovation and to remain responsive to the environment of the time, including a flexible approach as to how treatments and training are not only funded, but structured. Edith Kurzweil is quoted in the history of German psychoanalysis, making the point that a country gives rise to the form of psychoanalysis it needs. The example of the growth of psychoanalysis in China since the end of the Cultural Revolution (where there is now a rigorous 3-year analytic training for psychiatrists and psychologists) illustrates not just this sentiment, but the importance of creating a training programme capable of providing the treatments that a country can use at that particular point in time.

For the reader without a particular interest in psychoanalysis or psychotherapy there is still much of interest and relevance within the book, especially in the current climate of enforced change and upheaval within the NHS. Reading the book leaves one in no doubt as to the importance of the emotional life of an organisation and how this can affect its functioning. The value of holding onto the history, in particular the importance of the 'primal scene' of an organisation to its subsequent growth and development, is illustrated time and again. The histories of those groups who had their primal scenes or conceptions in the product of a forced marriage or a brutal takeover - and how those traumas affected not just their emotional life, but their smooth running until the trauma was processed - seems particularly relevant when similar events seem to be happening within different parts of the NHS today. It is in this area that the book, and the IPA, provides an eloquent and convincing argument for the importance of continually developing a rigorous and structured approach to understanding the present through an honest appraisal of past and current emotions, conscious or otherwise.

Paul MacAllister Specialist Registrar, Wells Road Centre for Community Forensic Psychiatry, Wells Road, Nottingham NG3 3AA, UK. Email: paul.macallister@nottshc. nhs.uk

doi: 10.1192/bjp.bp.111.107169

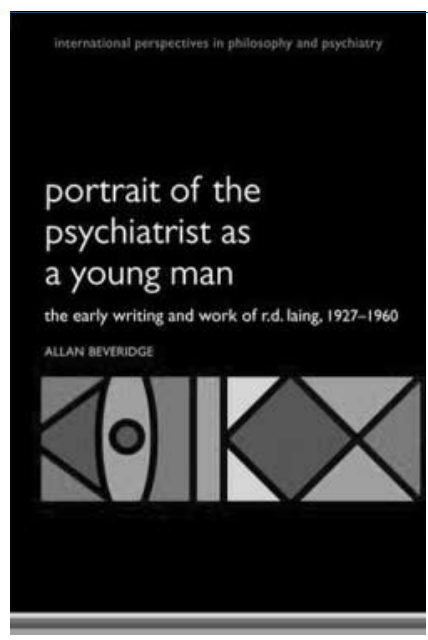

\section{Portrait of the Psychiatrist} as a Young Man The Early Writing and Work of R. D. Laing, 1927-1960

By Allan Beveridge. Oxford University Press. 2011. f39.99 (pb). $384 \mathrm{pp}$ ISBN: 9780199583577

The memory of R. D. Laing, the most famous British psychiatrist to date, refuses to fade almost 25 years after his death. In 2011, a plaque was unveiled in his honour at his childhood home in 